\title{
Acute effects of exposure to air contaminants in a sawmill on healthy volunteers
}

\author{
M Dahlqvist, L Palmberg, P Malmberg, B-M Sundblad, U Ulfvarson, W Zhiping
}

\begin{abstract}
Objectives-To study whether air contaminants in sawmills can induce acute changes in the upper and lower airways of previously non-exposed subjects.

Methods-Nineteen healthy volunteers were examined to find the concentration of interleukin 6 (IL-6) in nasal lavage fluid and lung function before and after five hour exposure to dusts and fumes generated in a sawmill where timber from Scots pine was sawed. When exposed, the subjects had respirators with and without a particle filter.

Results-The median for daily time weighted average concentration of total dust for subjects with respirators without a filter was $0.13 \mathrm{mg} / \mathrm{m}^{3}$, which was significantly higher than the median of 0.04 $\mathbf{m g} / \mathbf{m}^{3}$ for subjects who had respirators with a filter. The median for the concentration of IL-6 in the nasal lavage fluid increased after exposure from 0.5 to 5.9 $\mathrm{pg} / \mathrm{ml}$ in subjects with respirators without a particle filter $(P<0.05)$. The increase of the concentration of IL-6 was significantly correlated with the dust concentration. A decrease in transfer factor of the lung was significantly correlated with daily time weighted average concentrations of terpenes.
\end{abstract}

Conclusion-The findings suggest that healthy volunteers, exposed to air contaminants in a sawmill, show a slight inflammatory reaction. Also, the results of the study indicate the importance of decreasing the concentrations of wood dust in the work environment.

Department of Technology and Work

Science, Royal

Institute of

Technology,

Stockholm, Sweden

M Dahlqvist

U Ulfvarson

Respiratory Division, National Institute of Working Life,

Stockholm, Sweden

L Palmberg

P Malmberg

B-M Sundblad

W Zhiping

Correspondence to: M Dahlqvist, Royal Institute of Technology, Department of Environmental

Technology and Work

Technology and Work

S-100 44 Stockholm, Sweden.

Accepted 26 March 1996
(Occup Environ Med 1996;53:586-590)

Keywords: biological exposure indicator; interleukin; particle filtration; terpenes; wood dust

As early as the 18th century, Ramazzini decribed irritation of mucous membranes after exposure to air contaminants in connection with wood processing. ${ }^{1}$ A correlation between exposure to wood dust and obstructive lung disease was established about 200 years later. ${ }^{2}$ generated in sawmills may cause impairment of lung function. ${ }^{34}$ Several studies have been performed on wood trimmers, who sort and trim sawn and dried wood, and are exposed to fungi generated in the drying process. ${ }^{56}$ Recently a study indicated that sawyers have Earlier studies suggest that exposure to dusts lower transfer factors in the lung, and airways that are more responsive to methacholine than wood trimmers or controls working in the same sawmills. ${ }^{7}$ This finding suggests that agents released during the sawing process may affect airways. It is well known that plicatic acid in western red cedar (Thuja plicata) may cause asthma. ${ }^{8}$ Plicatic acid is, however, not present in Scots pine and Norway spruce, which are the main materials used in Swedish sawmills. Pine, and to a lesser extent, spruce are, however, rich in rosin (colophony) and terpenes. Rosins and terpenes, particularly in an oxidised form are potent skin sensitisers, ${ }^{9-11}$ and might affect airways as well. The present investigation was designed to study whether air contaminants in sawmills can induce acute changes in the upper and lower airways of previously non-exposed subjects. Volatiles, such as terpenes, and wood particles with rosins and terpenes, might contribute to such an effect. The subjects were therefore exposed in a blind fashion either to unfiltered sawmill air, or to air from which particles were removed with a filter. The proinflammatory cytokine interleukin (IL-6) was used as a marker of airway inflammation.

\section{Material and methods \\ STUDY GROUP}

Nineteen healthy volunteers, average age 26 (range 20-45), participated in the study. The subjects were men who gave negative answers to questions about airway or lung disease and atopy, being non-smokers during the past six months, and had never worked as a sawyer or with wood processing.

\section{STUDY DESIGN}

The study was carried out for two weeks in February. Each volunteer was examined in the afternoon once when unexposed and once when exposed. Baseline values (unexposed) were obtained two to three days before the exposure. The exposure took place in a sawmill sawing Scots pine (Pinus sylvestris) and the volunteers spent five hours in the sawmill, close to the area where timber was sawn. During the exposed occasion respirators (Racal Health and Safety, Järfälla, Sweden) connected to battery driven blower unit (Dustmaster MKII, Racal Health and Safety, Järfälla, Sweden) mounted in a belt, were used. Ten volunteers used respirators in which the blower unit had been equipped with a particle filter (THP2 according to European Standard) and nine used respirators without a 
particle filter. There were no significant differences in age, height, or weight between the two groups (table 1 ).

EXPOSURE ASSESSMENT

Exposure assessments of dust, the sum of terpenes and endotoxin were carried out with personal sampling, where the sampling point was located inside the respirator. Total dust was collected on cellulose acetate filters mounted in a $25 \mathrm{~mm}$ sampling head. Personal sampling of total dust was also carried with the sampling point located on the shoulder of the subject. Endotoxin was sampled on IOM samplers (SKC, PA, USA). The samplers were connected to battery powered pumps carried by the men, with a flow rate of about $2 \mathrm{l} / \mathrm{min}$. During sampling for dust, the sum of terpenes and endotoxin were measured for every subject for the whole exposure time, five hours. The filters were weighed before and several days after sampling. The detection limit for total dust was $0.1 \mathrm{mg}$ corresponding to $0.01-0.02 \mathrm{mg} / \mathrm{m}^{3}$. The concentration of endotoxin was analysed by Limulus amoebocyte lysate test, (QCL-1000 Endotoxin, BioWhittaker, Walkerswille, USA) with Escherichia coli 0111-B4 as standard. The detection limit was $0 \cdot 1$ endotoxin unit $/ \mathrm{ml}$ $(\simeq 0.008 \mathrm{ng} / \mathrm{ml})$.

The sum of terpenes ( $\alpha$-pinene, $\beta$-pinene, and $\Delta-3$-carene) was collected by diffusive samplers with charcoal (SKC, PA, USA). The samplers were stored in a freezer at $-20^{\circ} \mathrm{C}$ before the analysis (about seven days after sampling). The terpenes were analysed on a gas chromatograph with a flame ionisation detector. ${ }^{12}$

\section{BIOLOGICAL EFFECT INDICATORS}

The biological effect indicators included nasal lavage, spirometry, measurements of the transfer factors of the lung, and bronchial provocation with methacholine. A nasal lavage procedure described earlier by Bascom and coworkers and Pipkorn and coworkers ${ }^{1314}$ was used with minor modifications. The subject flexed the neck $45^{\circ}$ backwards and closed the soft palate while $5 \mathrm{ml} 0.9 \% \mathrm{NaCl}$ was instilled into one nostril, with a needleless syringe. After 10 seconds the neck was flexed forwards and the liquid was expelled into a plastic basin which was placed on ice during processing. The procedure was repeated on the other side. The volume of the combined lavage portions were measured and centrifuged for 10 minutes at $200 \mathrm{~g}$ at a temperature of $4^{\circ} \mathrm{C}$ and the supernatant was frozen at $-70^{\circ} \mathrm{C}$ for later analysis. The median (interquartile range) amount of nasal lavage fluid recovered was $7 \cdot 5$ $(7 \cdot 1-7 \cdot 9) \mathrm{ml}$. The cell pellet was suspended in balanced salt solution and the number of cells

Table 1 Characteristics (median (interquartile range)) for subjects with and without a particle filter

\begin{tabular}{lcc}
\hline & With particle filter $(n=10)$ & Without particle filter $(n=9)$ \\
\hline Age $(\mathrm{y})$ & $25(23-28)$ & $25(22-26)$ \\
Height $(\mathrm{cm})$ & $180(\mathbf{1 7 5}-\mathbf{1 8 8})$ & $181(181-190)$ \\
Weight $(\mathrm{kg})$ & $82(78-85)$ & $74(68-80)$ \\
\hline
\end{tabular}

were counted in a Bürker chamber. The concentration of IL-6 was analysed in the supernatant by means of commercial ELISA kits with monoclonal antibodies to human tissue (Quantikine high sensitivity kits, R\&D systems, Minneapolis, MN, USA). The standard curves were constructed with dilution of recombinant human IL-6 supplied with the kit. All assays were done in duplicate, with a four parameter logistic curve fit. The minimum detectable concentration of IL- 6 was $0.156 \mathrm{ng} / \mathrm{l}$ with the standard curve generated from the serum/plasma calibrator diluent. Spirometry was carried out with a calibrated wedge spirometer (Vitalograph, Buckingham, England) according to the guidelines given by the American Thoracic Society. The subject wore a nose clip and was asked to inhale as much as possible and thereafter exhale completely in a mouthpiece. Three slow vital capacity (VC) manoeuvres were carried followed by measurements of forced expiratory vital capacity (FVC) and forced expired volume in one second $\left(\mathrm{FEV}_{1}\right)$. The highest value of three $\mathrm{FEV}_{1}$ recordings was used. The VC was measured as the highest value of three forced and three slow vital capacities. Measurements of the transfer factor of the lung for carbon monoxide (TLCO) was carried out by means of the single breath technique with a Morgan transfer test model (PK Morgan, Chatman, England) according to the guidelines given by the European Respiratory Society. Reference values for spirometry and transfer factor were calculated from values given by equations published by Hedenström and colleagues. ${ }^{15}$

A jet nebuliser (Astra Meditec, model MA2, Gothenburg, Sweden) driven by compressed air $(390 \mathrm{kPa})$ was used for the bronchial provocation with a modified tidal breathing method. The subject inhaled the wet aerosol of saline solution then inhaled methacholine in increasing concentrations starting with 0.5 $\mathrm{mg} / \mathrm{ml}$. Each step meant a fourfold increase in the concentration of methacholine in saline. Measurements of $\mathrm{FEV}_{1}$ were carried out on the previously described spirometer and began four minutes after the end of the inhalations. The time between the concentration steps was six minutes. The provocation stopped when FEV 1 had decreased $20 \%$ compared with the value obtained after the diluent or until the maximum concentration of methacholine (32 $\mathrm{mg} / \mathrm{ml}$ ) was reached. The cumulative dose of inhaled methacholine was calculated from the nebuliser output and the time. The slope of the relation between $\mathrm{FEV}_{1}$ (expressed as a percentage of the mean of the diluent values before and after exposure) and the cumulative methacholine dose (linear scale) was calculated by linear regression. The method has been described in detail elsewhere. ${ }^{16}$

STATISTICAL ANALYSIS

Values are expressed as median and interquartile ranges if not otherwise stated. Differences between mean values between the two groups were tested by means of the Mann-Whitney test. Possible relations between the exposure 
Table 2 Time weighted average values (median (interquartile range)) of total dust, the sum of terpenes, and the corresponding hygienic limit values

\begin{tabular}{|c|c|c|c|}
\hline & $\begin{array}{l}\text { With particle filter } \\
(n=10)\end{array}$ & $\begin{array}{l}\text { Without particle filter } \\
(n=9)\end{array}$ & Hygienic limit value \\
\hline $\begin{array}{l}\text { Total dust }\left(\mathrm{mg} / \mathrm{m}^{3}\right) \\
\text { Terpenes }\left(\mathrm{mg} / \mathrm{m}^{3}\right)\end{array}$ & $\begin{array}{l}0.04(0.04-0.06)^{\star} \\
58(46-72)\end{array}$ & $\begin{array}{l}0.13(0.08-0.16) \\
52(42-74)\end{array}$ & $\begin{array}{l}2 \dagger \\
150\end{array}$ \\
\hline
\end{tabular}

${ }^{\star} 0.01<\mathrm{P}<0.001 v$ value obtained without particle filter.

†For wood dust.

Table 3 Median (interquartile range) number of cells/ml nasal lavage fluid and the concentration of Il-6 in the nasal lavage fluid before and after five hours of exposure in the savmill

\begin{tabular}{lll}
\hline & With particle filter $(n=10)$ & Without particle filter $(n=9)$ \\
\hline Cells $\times 10^{3} / \mathrm{ml}:$ & & \\
$\quad$ Before & $3.3(0.9-11 \cdot 6)$ & $1.0(0.4-14 \cdot 7)$ \\
After & $4.0(1 \cdot 1-15 \cdot 1)$ & $2.5(1 \cdot 5-19 \cdot 0)$ \\
Il-6 $(\mathrm{pg} / \mathrm{ml}):$ & $0.9(0.3-2 \cdot 4)$ & $0.5(0.4-2 \cdot 5)$ \\
$\quad$ Before & $0.7(<0.16-3 \cdot 7)$ & $5.9(4.5-23 \cdot 0)^{\star}$ \\
After & &
\end{tabular}

$\star \mathrm{P}<0.05 v$ subjects with particle filter and $v$ baseline value.

Table 4 Median (interquartile range) of lung function and bronchial reactivity after exposure (as \% of values before exposure) for subjects with and without a particle filter

\begin{tabular}{lcc}
\hline & With particle filter $(n=10)$ & Without particle filter $(n=9)$ \\
\hline FVC & $99(98-101)$ & $100(98-102)$ \\
FEV & $100(98-100)$ & $100(98-103)$ \\
TLCO & $102(98-104)$ & $99(95-104)$ \\
PC & $123(84-171)$ & $100(98-215)$ \\
Slope & $86(53-116)$ & $83(37-118)$ \\
\hline
\end{tabular}

variables and the biological exposure indicators was examined by means of Spearman's rank correlation analysis. A $P$ value $\geqslant 0.05$ (two tailed test) was considered to be significant unless otherwise stated.

\section{Results}

Daily time weighted average values for total dust, sampled inside the respirator, were significantly lower for subjects wearing a respirator equipped with a particle filter (table 2 ). The median concentration of total dust when four pairwise measurements had been carried out inside and outside the respirator was 0.12 and $0.17 \mathrm{mg} / \mathrm{m}^{3}$, respectively. The distributions of the measured monoterpenes between the groups with and without a particle filter in the respirators were identical and were made up of $64 \% \alpha$-pinene, $5 \% \beta$-pinene and $31 \% \Delta-3$ carene. The analysed concentrations of endotoxin were below the detection limit. There were no significant differences in the number of cells in the nasal lavage fluid after exposure between subjects with and without a particle filter. In the sawmill the concentration of IL-6 was significantly higher in subjects without a particle filter (table 3 ). There were no significant differences in FVC, FEV percentages of reference values ${ }^{15}$ between subjects with and without a particle filter $(P<0 \cdot 6)$. Median (25th-75th quartiles) for

Table 5 Spearman's rank correlation coefficients between the concentrations of monoterpenes and the change in TLCO after exposure for subjects with and without a particle filter

\begin{tabular}{llll}
\hline & $\alpha$-pinene & $\beta$-pinene & $\Delta$-3-carene \\
\hline With particle filter $(\mathrm{n}=10)$ & -0.28 & -0.38 & -0.29 \\
Without particle filter $(\mathrm{n}=9)$ & $-0.60^{\star}$ & $-0.63^{\star}$ & $-0.60^{\star}$ \\
\hline $\mathrm{P}^{\star}<0.05$ & &
\end{tabular}

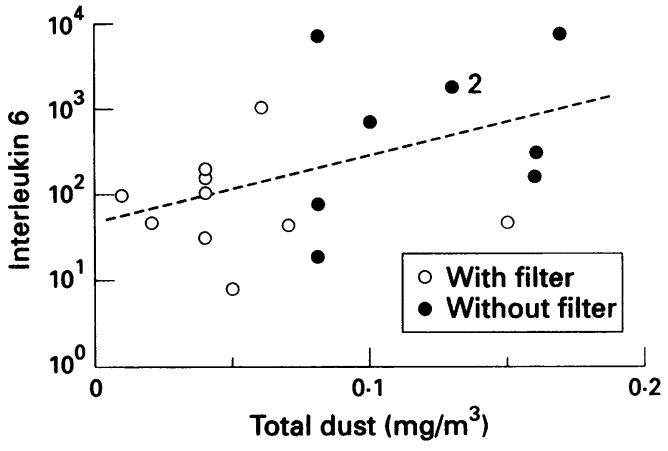

Figure 1 The relation between change in $I L-6$ in the nasal lavage fluid after exposure as a percentage of the unexposed value (log scale) and time weighted average concentrations of total dust. Values after exposure with and without a particle filter are shown $(n=19, \rho=0.43$, $P<0.05$, one tailed test).

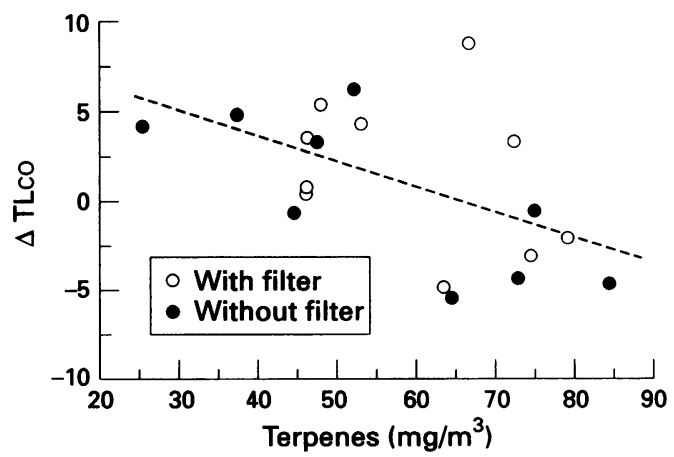

Figure 2 The relation between change in TLCO after exposure and time weighted average concentrations of the sum of terpenes. Values after exposure with and without a particle filter are shown $(n=19, \rho=0.46, P<0.05$, one tailed test).

FVC, $\mathrm{FEV}_{1}$, and TLCO as percentages of reference values ${ }^{15}$ for all 19 subjects were 99 (91-102), 99 (93-113), and 121 (108-137), respectively. There were no significant differences in the change of FVC, FEV , and TLCo after exposure in subjects with and without a particle filter (table 4). The average changes in bronchial responsiveness after exposure were comparable for subjects wearing a respirator with and without a particle filter (table 4). The increase in IL-6 in the nasal lavage fluid after exposure was correlated with daily time weighted average values for total dust $(\rho=$ $0.43, P<0.05$, one tailed test, fig 1 ). The decreases after exposure in TLCO and alveolar volume were correlated with daily time weighted average values for the sum of terpenes $(\rho=-0.46$ and $\rho=-0.47 ; \mathrm{P}<0.05$, one tailed test, fig 2). The change in TLCo was also significantly correlated with the concentrations of the monoterpenes $\alpha$-pinene, $\beta$ pinene, and $\Delta$-3-carene $(\rho=-0.49 ; \rho=$ $-0.53 ; \rho=-0.46$, respectively). When the same analyses were carried out on each group separately, it was found that the correlations between the change in TLCO and the monoterpenes were only significant in subjects wearing a respirator without a particle filter (table 5).

\section{Discussion}

The aim of the present study was to study air- 
way changes induced by acute exposure to air from the sawing area of a sawmill. To differentiate the effects of particles and volatiles one group used air stream respirators equipped with a filter that removed airborne particles. The other group used the same kind of respirator but without a filter to increase comparability and to blind the exposure to the subject. The subjects were healthy non-atopic volunteers with no previous exposure to sawmill air to exclude any possible effects of sensitisation to sawmill dusts and volatiles. Baseline values were measured at the same time of the day as the values after exposure to minimise diurnal variation. This study design allows detection of very small changes, $<5 \%$ in the subjects examined. The use of a particle filter in the respirator decreased the concentration of total dust in the inspired air by about $60 \%$, but did not influence the concentration of volatiles (table 2). Even a respirator without a filter resulted in about $1 / 3$ less total dust than in air sampled from the shoulder. This is probably due to the sedimentation of dust on the fan blades and within the tubing supplying the helmet. The dust concentration was generally low and the daily time weighted average values of total dust corresponded to $6 \%$ of the Swedish hygienic limit for wood dust. Air contaminants in sawmills may cause air inflammation, associated with the release of proinflammatory cytokines such as IL-1, IL-6, and tumour necrosis factor- $\alpha$ (TNF- $\alpha$ ). In the present study we used IL- 6 as a marker of the release of inflammatory cytokines and thus of airway inflammation. Interleukin-6 together with IL-1 and TNF- $\alpha$ are potent inducers of systemic effects such as fever and malaise and can be found in nasal and bronchoalveolar lavage fluids and in peripheral blood after pronounced airway inflammation induced by toxic dusts. ${ }^{1718}$ In both groups there were nominal increases in cells and IL-6 concentrations in nasal lavage fluid, but the changes were greater in subjects not using a particle filter. The increase in IL-6 in subjects not using a filter was the only change in nasal lavage variables reaching significance (table 3). Inhalation of bacteria rich dusts from swine house buildings with endotoxin concentrations in the order of $1300 \mathrm{ng} / \mathrm{m}^{3}$ causes airway inflammation and increases in IL-6 concentrations in nasal lavage. ${ }^{15}$ In the present study, the concentrations of endotoxin were below the detection limit $\left(\simeq 0 \cdot 1 \mathrm{ng} / \mathrm{m}^{3}\right)$. It is therefore not probable that the increased concentration of IL-6 was caused by exposure to endotoxin, but rather by agents associated with the particles in sawmill air. Daily time weighted average concentrations of the sum of terpenes was about one third of the present hygienic limit value (table 2 ). There were no changes in spirometric values in the present study (table 4), but TLco correlated negatively with the sum of terpenes in the combined groups (fig 2). The correlation was, however, most pronounced in the group without a filter (table 5), although both groups had similar values for total terpenes (table 2). Particularly, Scots pine is rich in terpenes, which are released during the sawing of fresh pine. The terpenes reach the air associated with wood particles and are volatiles. It has been suggested that $\Delta-3$-carene can be oxidised into short lived reactive products, that may cause contact allergy. Wood particles also contain rosins, and in pine and spruce, the dominant resin acids of rosin are abietic acid and dihydroabietic acid. ${ }^{919}$ During contact with air, abietic and dihydroabietic acid is quickly oxidised to short lived and very potent contact allergens. ${ }^{10}$ We have no knowledge if such agents also cause acute effects, or if other constituents contribute to the effects we found. Some studies have indicated an inflammatory response after short term exposure to terpenes $^{2021}$ but other studies have not shown such effects. ${ }^{22} 23$

The results of studies on sawmill workers suggest chronic effects on airways, incuding changes in lung function over a workshift. ${ }^{56}$ Sawmill workers with a daily time weighted average concentration of terpenes varying between 100 and $550 \mathrm{mg} / \mathrm{m}^{3}$ showed a chronically decreased $\mathrm{FEV}_{1}$ and an increased tendency to airway closure. ${ }^{4}$ This study prompted measures to decrease the exposure to fumes of the sawmills, resulting in a decrease in the mean concentration of terpenes of about $85 \%$ and a significant improvement in lung function. ${ }^{24}$ The concentration of wood dust was about half of the present hygienic limit value and unaltered between the two study occasions. A problem in interpreting data from previous studies on sawmill workers is that previous studies have often focused on workers exposed to wood fungi in the trimming section of the sawmills. ${ }^{56}$ Thus in several studies it is not clear whether the suggested health effects resulted from exposure to air pollutants associated with sawing of timber or other exposures associated with the handling of wood that has passed the drying kilns. In one study, however, workers in the sawing department were compared with wood trimmers and workers outside the trimming and sawing areas and the sawyers were found to have lower transfer test values compared with controls, and an increased bronchial responsiveness. ${ }^{16}$

In conclusion, the findings of this study suggest that healthy volunteers, exposed to air contaminants in a sawmill, show a slight inflammatory reaction of the upper airways. Also the results indicate the importance of decreasing the concentrations of particles in the work environment.

This study was supported by grants AMFO 94-0563 from the Swedish Work Environmental Fund. We gratefully acknowledge the invaluable assistance of Björn Bergström, Ulla Ekholm, Kåre Eriksson, Britt-Marie Larsson, Charlotte Müller-Suur, and Siw Siljerud.

1 Sakula A. Ramazzini's De morbis artificum and occupationa lung disease. Br $\mathcal{F}$ Dis Chest 1983;77:349-61.

2 Ruppe $\mathrm{K}$. Diseases and functional disturbances of the respiRuppe K. Diseases and functional disturbances of the respiratory tract in workers of the woodworking industry. Zeitschrift fur die

3 Whitehead L. Health effects of wood dust-relevance for an occupational standard. Am Ind Hygiene Assoc $\mathcal{F} 1981$; 43:674-8.

4 Hedenstierna G, Alexandersson R, Wimander K, Rosén G. 
Exposure to terpenes: effects on pulmonary function. Int Arch Occup Environ Health 1983;51:191-8.

5 Johard U, Eklund A, Dahlqvist $M$, Ahlander A, Alexandersson R, Ekholm U, et al. Signs of alveolar inflammation in non-smoking Swedish wood trimmers. Br F Ind Med 1992;49:428-34.

6 Dahlqvist $M$, Johard U, Alexandersson $R$, Bergström $B$, Ekholm U, Eklund A, et al. Lung function and precipitating antibodies in low exposed wood trimmers in Sweden. Am f Ind Med 1992;21:549-59.

7 Malmberg P, Rask-Andersen A, Larsson KA, Stjernberg N, Sundblad B-M, Eriksson $\mathrm{K}$. Increased bronchial responsiveness in workers sawing Scots pine. Am $\mathcal{F}$ Respir Crit Care Med 1996;153:948-52.

8 Chan Yeung M, Vedal S, Kus J, MacLean M, Enarson D, Tse KS. Symptoms, pulmonary function and bronchial hyperreactivity in western red cedar asthma compared to office workers. Am Rev Respir Dis 1984;130:1038-41.

9 Gäfvert E. Allergenic components in modified and unmodified rosin. Acta Derm Venereol Suppl (Stoch) 1994;184: $1-36$.

10 Karlberg A, Bohlinder K, Boman A, Hacksell U, Hermansson J, Jacobsson S, Nilsson LG. Identification of 15-hydroperoxyabietic acid as a contact allergen in Portuguese colophony. F Pharm Pharmacol 1988;40:42-7.

11 Pirilä V. Eczema due to oil of turpentine. Therapeutische Umschau/Revue Thérapeutique 1970;27:509-14.

12 Eriksson $\mathrm{K}$, Levin J-O. Identification of cis- and trans-verbenol in human urine after occupational exposure to terpenes. Int Arch Occup Environ Health 1990;62:379-83.

13 Bascom R, Pipkorn U, Lichtenstein L, Naclerio R. The influx of inflammatory cells into nasal washings during the late response to antigen challenge. Am Rev Respir Dis 1988;138:406-12.

14 Pipkorn U, Karlsson G, Enerbäck L. A brush method to harvest cells from the nasal mucosa for microscopic and biochemical analysis. F Immunol Methods 1988;112: $37-42$.

15 Hedenström H, Malmberg P, Fridriksson HV. Reference values for lung function tests in men: regression equa- tions with smoking variables. Upsala f Med Sci 1986;91: 299-310.

16 Malmberg $P$, Larsson $K$, Thunberg $S$. Increased lung deposition and biological effect of methacholine by use of a drying device for bronchial provocation tests. Eur Respir f 1991;4:890-8.

17 Zhiping W, Malmberg P, Larsson K, Palmberg HL. Inhalation of swine dust induces cytokine release into upper and lower airway [abstract]. Eur Respir $\mathcal{f} 1995 ; 8$ (suppl 19):351s.

18 Zhiping W, Malmberg P, Larsson P, Larsson B-M, Larsson $K$. Time course of interleukin- 6 and tumor necrosis factor- $\alpha$ increase in serum following inhalation of swine tor- $\alpha$ increase in serum following inhalation

19 Bruun H, Gaslund S. Partition chromatographic studies of the rosin acid compositions of oleorosins from northEuropean pine and spruce, Finnish tall oil rosin and catalytically modified tall oil rosins. Acta Acad Abo. Mathematica et Physica XXII 1960;1:11-9.

20 Johard U, Larsson K, Löf A, Eklund A. Controlled shorttime terpene exposure induces an increase of the macrophages and the mast cells in bronchalveolar lavage fluid. Am F Ind Med 1993;23:793-9.

21 Johard U, Eklund A, Hed J, Lundahl J. Terpenes enhance metabolic activity and alter expression of adhesion molecules (Mac-1 and L-Selectin) on human granulocytes. Inflammation 1992;17:499-509.

22 Falk A, Hagberg MT, Löf AE, Wigaeus Hjelm EM, Zhiping $W$. Uptake, distribution and elimination of $\alpha$ pinene in man after exposure by inhalation. Scand $₹$ Work pinene in man after exposure by

23 Falk A, Löf A, Hagberg M, Wigaeus-Hjelm E, Wang Z. Human exposure to 3 -carene by inhalation: toxicokinetics, effects on pulmonary function and occurence of irritative and CNS-symptoms. Toxicol Appl Pharmacol 1991; 110:198-205.

24 Dahlqvist $M$, Alexandersson $R$, Ulfvarson U. Pulmonary function changes in sawmill workers - a prospective study of occupational exposure to sawfumes. Occup Hyg 1994;1:17-26.

\section{Correspondence and editorials}

Occupational and Environmental Medicine welcomes correspondence relating to any of the material appearing in the journal. Results from preliminary or small scale studies may also be published in the correspondence column if this seems appropriate. Letters should be not more than 500 words in length and contain a minimum of references. Tables and figures should be kept to an absolute minimum. Letters are accepted on the understanding that they may be subject to editorial revision and shortening.

The journal also publishes editorials which are normally specially commissioned. The Editor welcomes suggestions regarding suitable topics; those wishing to submit an editorial, however, should do so only after discussion with the Editor. 